Article

\title{
Anticoccidial Effect of Herbal Powder "Shi Ying Zi" in Chickens Infected with Eimeria tenella
}

\author{
Xu Song ${ }^{+} \mathbb{D}$, Yunhe $\mathrm{Li}^{\dagger}{ }^{+}$, Shufan Chen ${ }^{\dagger}$, Renyong Jia, Yongyuan Huang, Yuanfeng Zou ${ }^{\mathbb{D}}, \mathrm{Lixia}$ Li, \\ Xinxin Zhao and Zhongqiong Yin * \\ Natural Medicine Research Center, College of Veterinary Medicine, Sichuan Agricultural University, \\ Chengdu 611130, China; songx@sicau.edu.cn (X.S.); lytranh@163.com (Y.L.); chensf940824@163.com (S.C.); \\ cqrc_jry@163.com (R.J.); h415267256@163.com (Y.H.); yuanfengzou@sicau.edu.cn (Y.Z.); \\ lilixia905@163.com (L.L.); xxinzhao@163.com (X.Z.) \\ * Correspondence: yinzhongq@sicau.edu.cn; Tel.: +86-28-86291470 \\ + Contributed equally to this work.
}

Received: 6 July 2020; Accepted: 20 August 2020; Published: 24 August 2020

check for updates

Simple Summary: Herbal medicines are playing an increasingly important role in the control of poultry diseases. The present study demonstrated that the herbal powder "Shi Ying Zi" consisting of Cnidium monnieri (L.) Cuss, Taraxacum mongolicum Hand.-Mazz., and sodium chloride could protect chickens from infection with Eimeria tenella through prophylactic or therapeutic administration. The "Shi Ying $\mathrm{Zi}$ " powder could improve the survival rate and relative growth rate with the anti-coccidial indexes of 165 (prophylactic effect) and 144 (therapeutic effect), which were equal to positive controls (monensin and sulfamlopyrazine). The "Shi Ying Zi" powder exhibits the potential to control E. tenella infection.

Abstract: Coccidiosis is one of the most economically important diseases affecting the poultry industry. Currently, anticoccidial drugs used in veterinary clinics show many deficiencies, and new control measures are urgently needed. This study presents an anticoccidial herbal powder "Shi Yin Zi", which consists of Cnidium monnieri (L.) Cuss, Taraxacum mongolicum Hand.-Mazz., and sodium chloride. In chickens infected with Eimeria tenella, supplementation with "Shi Yin $\mathrm{Zi}$ " powder for $3 \mathrm{~d}$ prior to infection or treatment with "Shi Yin $\mathrm{Zi}^{\prime}$ powder after infection could improve the survival rate and relative growth rate and alleviate the pathological changes in the cecum, liver, and kidney. "Shi Yin $\mathrm{Zi}$ " powder could recover the levels of alanine aminotransferase, creatinine, albumin, and triglycerides in serum. The hemorrhage occurrence and total number of oocysts in feces were reduced. The anti-coccidial indexes reached 165 for the prophylactic effect and 144 for the therapeutic effect. The anti-coccidial effects were equal to positive controls (monensin and sulfamlopyrazine). These results suggest that "Shi Ying Zi" powder possesses a potent anticoccidial effect and exhibits the potential to control E. tenella infection.

Keywords: anticoccidial drug; coccidiosis; "Shi Yin Zi" powder

\section{Introduction}

Coccidiosis, which is caused by seven species of intracellular protozoan parasites of the genus Eimeria, is one of the most detrimental and lethal diseases of commercial poultry flocks [1]. It is a rapidly developing intestinal disease that presents with bloody diarrhea and listlessness and can cause high levels of mortality in affected flocks [2]. Eimeria oocysts are highly infectious and resilient [3]. The primary sources of the spread of oocysts are usually rodents, insects, and wild birds, and their development is favored by moisture and heat, which are not lacking in poultry farms [4]. Eimeria oocysts 
typically invade intestinal epithelium cells and cause destruction of the infected cells, resulting in a reduction of feed conversion, body weight gain, and egg production, and increased morbidity and mortality [5]. Eimeria tenella is one of the most frequent and destructive pathogens of the genus Eimeria. It parasitizes chicken cecum and induces bloody excrement and body weight reduction [6]. Therefore, the management of coccidiosis and maintenance of the immune functions for ensuring maximum performance, growth, and production in the poultry industry are fundamental requirements for profitable farming [7]. In the prevention of coccidiosis, good sanitary conditions of poultry farms, such as maintaining cleanliness, good ventilation, and the regular replacement of litter, are important for eliminating dampness and the appearance of mold, which create an ideal environment for protozoa to thrive. Furthermore, nets that prevent rodents, insects, and wild birds from entering the farms also play an important role. The regular administration of coccidiostats in feed and preventive vaccinations are typical methods used to control the disease, but coccidial oocysts gradually show drug tolerance and the production capacity of current vaccine lines is limited [8,9]. To prevent the emergence of drug resistance, new drugs have been developed and administered on a rotational basis with existing drugs. However, this has resulted in an increased cost of poultry products. Furthermore, anticoccidial drug residues in poultry products are potentially an annoyance to consumers [8]. In recent years, anticoccidial drug development has been slower than the emergence of drug-resistant Eimeria spp., which has stimulated the search for alternative control methods for avian coccidiosis [10].

There are many plant-derived drugs with anticoccidial effects, such as herbal extracts [11,12]. Compared with chemotherapeutic drugs, anticoccidial herbal medicines usually exhibit less drug residues and less drug resistance [13]. Cnidium monnieri (L.) Cuss. is a widely used traditional herbal medicine in China, Vietnam, and Japan, and its fruits have been used to treat a variety of diseases, including female vulva pain, male impotence, epilepsy, and ulcers [14]. Many phytochemicals, mainly coumarins, which are the dominant active constituents, have been identified from C. monnieri, and osthole is used as a quality marker in the Pharmacopoeia of China [15]. Taraxacum mongolicum Hand.-Mazz. is a Chinese medicine commonly used to treat infection, fever, upper respiratory tract infections, pneumonia, and other infectious diseases [16]. The phytochemical constituents of T. mongolicum can mainly be divided into sesquiterpenoid, triterpenoid, phytosterol, flavonoids, phenolic acids, and organic acids [17]. Caffeic acid, which is a kind of phenolic acid, is used as a quality marker in the Pharmacopoeia of China. Based on the traditional Chinese veterinary medicine theory, unlike other herbal extracts, this study prepared the herbal formula "Shi Ying Zi", which is a powder consisting of a mixture of $C$. monnieri, T. mongolicum, and sodium chloride at a ratio of 55:40:5. The anticoccidial effects of "Shi Ying $\mathrm{Zi}^{\mathrm{i}}$ " powder were evaluated in chickens infected with E. tenella through supplementation for $3 \mathrm{~d}$ prior to infection and administration after infection for determination of the preventive and therapeutic effects of "Shi Ying $\mathrm{Zi}$ " powder.

\section{Materials and Methods}

\subsection{Preparation of "Shi Ying Zi" Powder}

"Shi Ying Zi" powder consisted of C. monnieri, T. mongolicum, and sodium chloride at a ratio of 55:40:5. The two herbals were procured from Baicaotang pharmaceutical chain Co. LTD (Chengdu, China). The samples of the two plant materials were deposited at the herbarium of the Natural Medicine Research Center, College of Veterinary Medicine, Sichuan Agricultural University (Chengdu, China), with voucher numbers 2017-0168 and 2017-0205, respectively. The content of osthole in C. monnieri was $1.28 \%$ and the content of caffeic acid was $0.041 \%$ in T. mongolicum Hand-Mazz. The quality criteria of the two herbals were fitted for the standards of the Pharmacopoeia of China (Version 2015, China Pharmacopoeia Committee). The mixtures of C. monnieri, T. mongolicum, and sodium chloride were smashed into powder, followed by sieving through $150 \mu \mathrm{m} \pm 6.6 \mu \mathrm{m}$ screen cloth, to give the "Shi Ying Zi" powder. 


\subsection{Oocyst}

The sporulated oocysts of E. tenella (BJ strain) were provided by the College of Veterinary Medicine, China Agricultural University (Beijing, China) [18]. For the propagation of oocysts, twenty 14-day-old chicks free of coccidiosis were inoculated with $2 \times 10^{4}$ sporulated oocysts of E. tenella by oral gavage. The cecum contents and feces from infected chicks were collected at 7 days post infection (dpi), and oocysts were separated by flotation in saturated saline, as described by Kumar (2014) [19]. The oocysts were then allowed to sporulate in $2.5 \%(w / v)$ potassium dichromate solution at $28{ }^{\circ} \mathrm{C}$ for three days, followed by washing thrice with normal saline. After the determination of the total number of oocysts by the McMaster technique, as previously described [20], the sporulated oocysts were diluted to $2 \times 10^{4}$ oocysts $/ \mathrm{mL}$ in normal saline.

\subsection{Experimental Design}

Two hundred 1-day-old broiler chicks free of coccidiosis were purchased from a commercial hatchery (Tianchi Poultry Co. Ltd., Mianyang, China) and reared in a sterilized poultry shed of the animal houses of Sichuan Agricultural University (Ya'an, China). The chicks were fed a ${ }^{60} \mathrm{Co}$-sterilized diet free of anticoccidial drugs (Supplementary Table S1; Xietong Biotechnology Co., Ltd., Nanjing, China). The feces were collected daily to check for oocysts [21]. At the 11th day of age, the chicks were all free of coccidiosis and were then equally divided into 10 groups (10 males and 10 females per group and each with four replicates of five chickens/cage), including an uninfected-untreated group, an infected-untreated group, four prophylactic groups (positive control group and three "Shi Ying $\mathrm{Zi}$ " powder groups), and four therapeutic groups (positive control group and three "Shi Ying $\mathrm{Zi}$ " powder groups). The chicks in the three "Shi Ying Zi" powder protective

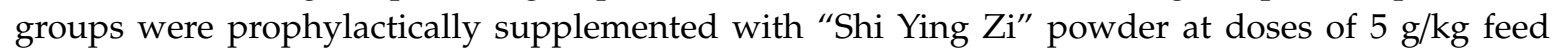
(ShiYingZi-PL), $10 \mathrm{~g} / \mathrm{kg}$ feed (ShiYingZi-PM), and $15 \mathrm{~g} / \mathrm{kg}$ feed (ShiYingZi-PH), respectively. In the positive control group, monensin was added $(100 \mathrm{mg} / \mathrm{kg}$ feed). For obtaining homogeneous mixtures of feed with "Shi Ying Zi", the powder was firstly mixed with an equal quantity of feed, and the feed was added to the mixture at an equal quantity. The mixing process continued until all of the feed had been added. The uninfected-untreated group and infected-untreated group were fed a regular diet. At the 14th day of age, chicks, except for those in the uninfected-untreated group, were inoculated with $2 \times 10^{4}$ sporulated oocysts of E. tenella by oral gavage. At 1 dpi, the chicks in the three "Shi Ying $\mathrm{Zi}^{\prime \prime}$ powder therapeutic groups were supplemented with "Shi Ying $\mathrm{Zi}^{\prime}$ powder at doses of $5 \mathrm{~g} / \mathrm{kg}$ feed, (ShiYingZi-TL), $10 \mathrm{~g} / \mathrm{kg}$ feed (ShiYingZi-TM), and $15 \mathrm{~g} / \mathrm{kg}$ feed (ShiYingZi-TH), respectively. In the positive control group, sulfachloropyrazine sodium was added to water $(1 \mathrm{~g} / \mathrm{L})$.

\subsection{Ethical Approval}

All procedures involving animals and their care in this study were approved by the Ethics Committee of Sichuan Agricultural University according to the Regulation of Experimental Animal Management (State Scientific and Technological Commission of the People's Republic of China, No. 2, 1988) and The Interim Measures of Sichuan Province Experimental Animal Management (Science and Technology Bureau of Sichuan, China, No. 25, 2013). At the end of the study ( $8 \mathrm{dpi}$ ), the chicks were anesthetized through intravenous injection (underwing vein) with sodium pentobarbital $(30 \mathrm{mg} / \mathrm{kg}$ body weight) within 2 min of the birds being removed from their home pen [22]. The wing venous blood samples and tissue samples (five chicks per group) were collected. The rest of the anesthetized chicks were euthanized by manual cervical dislocation. All efforts were made to minimize the suffering of birds.

\subsection{Clinical Symptoms}

The chicks were examined daily for recording clinical signs, such as anorexia, huddling together, disheveled feathers, bloody stools, and mortality [23]. 


\subsection{Bloody Diarrheal Score}

The bloody diarrheal score is a qualitative estimation of the deviation of the fecal appearance from a normal state. It was obtained by scoring the bloody feces each morning from 4 to $8 \mathrm{dpi}$. The bloody diarrheal score ranged from 0 to 4 : A score of 0 indicated normal feces without hemorrhage; a score of 1 indicated 1-25\% hemorrhage in the feces; a score of 2 indicated $25-50 \%$ hemorrhage in the feces; a score of 3 indicated $51-75 \%$ hemorrhage in the feces; and a score of 4 indicated $76-100 \%$ hemorrhage in the feces [11].

\subsection{Lesion Score of the Cecum}

The postmortem examination was conducted $8 \mathrm{dpi}$. The dead and slaughtered birds were incised, and gross lesions in the cecum were examined by recording lesion scoring as described by Johnson and Reid [24]. The lesions included hemorrhages, thickening of the cecum wall, and mucoid discharge. The lesion score ranged from 0 to 4: A score of 0 indicated no lesion; a score of 1 indicated a mild lesion; a score of 2 indicated a moderate lesion; a score of 3 indicated a severe lesion; and a score of 4 indicated a more severe lesion.

\subsection{Oocyst Counts}

The oocyst counts in feces were measured by the McMaster method [20]. Briefly, $2 \mathrm{~g}$ of feces collected from 0 to 8 dpi were uniformly dispersed in $60 \mathrm{~mL}$ saturated salt solution with vigorous stirring, followed by filtration. Then, the filtrate was loaded onto a McMaster Egg Slide (Chongqing DiShui Experimental apparatus Co., Ltd., Chongqing, China), which has two chambers with two identical $10 \mathrm{~mm} \times 10 \mathrm{~mm} \times 1.5 \mathrm{~mm}$ grids $(0.15 \mathrm{~mL})$, for oocyst counting. The total number of oocysts under both of the grids was recorded. The oocyst counts (oocysts per gram) were calculated by multiplying the total number of oocysts in the two chambers by 100 . The cecum contents were collected $8 \mathrm{dpi}$ after postmortem examination. The oocyst counts in the cecum contents were determined as described above. The score of the oocysts index at 8 dpi ranged from 0 to 40: A score of 0 indicated the oocyst counts were $0-0.1 \times 10^{6}$; a score of 5 indicated the oocyst counts were $0.11 \times 10^{6}-1 \times 10^{6}$; a score of 10 indicated the oocyst counts were $1.1 \times 10^{6}-1.9 \times 10^{6}$; a score of 20 indicated the oocyst counts were $2.0 \times 10^{6}-5.9 \times 10^{6}$; a score of 30 indicated the oocyst counts were $6.0 \times 10^{6}-10.9 \times 10^{6}$; and a score of 40 indicated the oocyst counts were more than $1.1 \times 10^{7}$.

\subsection{Anti-Coccidiosis Index}

The anti-coccidiosis index $(\mathrm{ACI})=($ Relative weight gain rate + Survival rate $)-($ Oocysts index in cecum + Gross lesions score) [25].

The relative weight gain rate $(\times 100 \%)$ is the ratio of the average weight gain of the infected group to the average weight gain of the uninfected-untreated group. The survival rate $(\times 100 \%)$ is the ratio of the number of alive chicks to the total number of chicks. The average initial weight is the average weight of the chicks at $0 \mathrm{dpi}$, and the average final weight is the average weight of the chicks at $8 \mathrm{dpi}$.

When ACI is larger than 180, it means that the drug has a high efficiency; when ACI is 160-180, it means that it has a medium efficiency; when ACI is 120-160, it means that it has a low efficiency; and when ACI is lower than 120, it means that the drug does not possess anti-coccidiosis effects.

\subsection{Biochemical Indexes}

For biochemical studies, 3-4 mL wing venous blood was collected from five randomly selected chicks of each group into tubes, without any anticoagulant, at intervals of 1, 4 and 8 dpi. After clotting, serum was separated and various parameters were estimated, including total serum protein, albumin, aspartate aminotransferase, alanine aminotransferase, creatinine, and triglyceride. The globulins were calculated by subtracting the values of albumin from total serum proteins. 


\subsection{Histopathology}

After dissection, the cecum, liver, and kidney tissue samples were subjected to common histological preparation. A $5 \mu \mathrm{m}$ section of each tissue was procured and stained with hematoxylin and eosin (HE) for histopathological examination.

\subsection{Statistical Analysis}

The statistical significance was compared for the uninfected-untreated control and experimental groups by one way analysis of variance (ANOVA), followed by the Student-Newman-Keuls test, using the IBM SPSS Statistics, Version 24 program (IBM Corporation. Somers, NY, USA). The differences between groups were considered significant when values of $p<0.05$.

\section{Results}

\subsection{Clinical Symptoms and Mortality}

After being challenged with E. tenella, the clinical signs and symptoms were closely monitored throughout the trial. The clinical signs, including disheveled feathers, dullness, and anorexia, were observed in the infected-untreated group at 3 dpi. The symptoms in ShiYingZi protective groups were observed at $4 \mathrm{dpi}$, which were similar to the infected-untreated group, but much milder. The mortality of the infected-untreated group was highest in all groups. The appearance of hemorrhage in feces was noted at $4 \mathrm{dpi}$ in the infected-untreated group and many oocysts were found in the cecum, suggesting that the model was successfully established. For pretreatment with "Shi Ying Zi" powder, bloody stools were detected at $5 \mathrm{dpi}$.

E. tenella infection induced a $25 \%$ mortality rate in the infected-untreated group, which is significantly higher than the uninfected-untreated control and other infected groups. Pretreatment with "Shi Ying Zi" powder only caused a 5\% mortality rate in the ShiYingZi-PL group and ShiYingZi-PH group. There was no mortality in the ShiYingZi-PM group and monensin group (Table 1). When the drugs were supplemented after infection, the mortality rates were $10 \%$ in the ShiYingZi-TL group and $5 \%$ in the ShiYingZi-TM group. In the ShiYingZi-TH group and sulfachloropyrazine sodium group, there was no mortality (Table 1). These results suggested that "Shi Ying Zi" powder and positive drugs could significantly reduce the mortality rate of chicks infected with E. tenella.

Table 1. Mortality in different groups from 4 to 8 days post infection (dpi).

\begin{tabular}{ccccccc}
\hline Groups & $\mathbf{4} \mathbf{d p i}$ & $\mathbf{5} \mathbf{d p i}$ & $\mathbf{6} \mathbf{d p i}$ & $\mathbf{7} \mathbf{d p i}$ & $\mathbf{8} \mathbf{d p i}$ & Total Mortality \\
\hline Uninfected-untreated control & 0 & 0 & 0 & 0 & 0 & $0^{\mathrm{a}}$ \\
Infected-untreated control & 2 & 2 & 1 & 0 & 0 & $5^{\mathrm{b}}$ \\
ShiYingZi-PL & 0 & 1 & 0 & 0 & 0 & $1^{\text {ac }}$ \\
ShiYingZi-PM & 0 & 0 & 0 & 0 & 0 & $0^{\mathrm{a}}$ \\
ShiYingZi-PH & 1 & 0 & 0 & 0 & 0 & $1^{\text {ac }}$ \\
Monensin & 0 & 0 & 0 & 0 & 0 & $0^{\mathrm{a}}$ \\
ShiYingZi-TL & 1 & 1 & 0 & 0 & 0 & $2^{\text {ac }}$ \\
ShiYingZi-TM & 0 & 1 & 0 & 0 & 0 & $1^{\text {ac }}$ \\
ShiYingZi-TH & 0 & 0 & 0 & 0 & 0 & $0^{\mathrm{a}}$ \\
Sulfachloropyrazine sodium & 0 & 0 & 0 & 0 & 0 & $0^{\mathrm{a}}$ \\
\hline a,b,c Different letters for the total mortality indicate that a significant difference existed $(p<0.05)$.
\end{tabular}

\subsection{Anticoccidial Efficacy in Chickens}

The bloody diarrheal score from 4 to $8 \mathrm{dpi}$ (Table 2) and the total number of oocysts per gram of feces from 0 to $8 \mathrm{dpi}$ (Table 3) were measured. Oocyst shedding in feces could be observed from 0 to $3 \mathrm{dpi}$. When the hemorrhagic feces were observed in the infected groups at $4 \mathrm{dpi}$, the oocyst shedding in feces could be detected, except for the ShiYingZi-PH and monensin groups. The number of oocysts in 
feces was decreased by ShiYingZi treatment from 4 to $8 \mathrm{dpi}$. The ShiYingZi therapeutic group $(10 \mathrm{~g} / \mathrm{kg})$ exhibited a significantly decreased bloody diarrheal score in comparison with the infected-untreated control at $5 \mathrm{dpi}$. Both the prophylactic and therapeutic administration of "Shi Ying Zi" powder could significantly decrease the bloody diarrheal score in comparison with the infected-untreated control

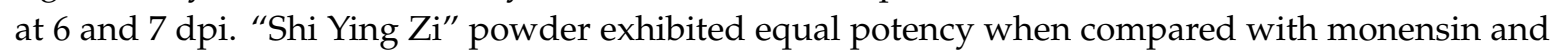
sulfachloropyrazine sodium. These results suggested that "Shi Ying $\mathrm{Zi}^{\prime \prime}$ powder could alleviate the hemorrhages in feces and accelerate recovery from bloody stools. The amount of oocyst shedding in feces was also reduced.

Table 2. The bloody diarrheal score from 4 to 8 dpi.

\begin{tabular}{cccccc}
\hline Groups & $\mathbf{4} \mathbf{d} \mathbf{p i}$ & $\mathbf{5} \mathbf{d p i}$ & $\mathbf{6} \mathbf{d p i}$ & $\mathbf{7} \mathbf{d p i}$ & $\mathbf{8} \mathbf{d} \mathbf{p i}$ \\
\hline Uninfected-untreated control & $0^{\mathrm{a}}$ & $0^{\mathrm{a}}$ & $0^{\mathrm{a}}$ & $0^{\mathrm{a}}$ & $0^{\mathrm{a}}$ \\
Infected-untreated control & $1^{\mathrm{a}}$ & $2^{\mathrm{b}}$ & $3^{\mathrm{b}}$ & $3^{\mathrm{b}}$ & $1^{\mathrm{a}}$ \\
ShiYingZi-PL & $1^{\mathrm{a}}$ & $2^{\mathrm{b}}$ & $3^{\mathrm{b}}$ & $2^{\mathrm{c}}$ & $1^{\mathrm{a}}$ \\
ShiYingZi-PM & $0^{\mathrm{a}}$ & $2^{\mathrm{b}}$ & $2^{\mathrm{c}}$ & $2^{\mathrm{c}}$ & $0^{\mathrm{a}}$ \\
ShiYingZi-PH & $1^{\mathrm{a}}$ & $2^{\mathrm{b}}$ & $3^{\mathrm{b}}$ & $3^{\mathrm{b}}$ & $0^{\mathrm{a}}$ \\
Monensin & $0^{\mathrm{a}}$ & $2^{\mathrm{b}}$ & $2^{\mathrm{c}}$ & $2^{\mathrm{c}}$ & $0^{\mathrm{a}}$ \\
ShiYingZi-TL & $0^{\mathrm{a}}$ & $2^{\mathrm{b}}$ & $3^{\mathrm{b}}$ & $2^{\mathrm{c}}$ & $0^{\mathrm{a}}$ \\
ShiYingZi-TM & $0^{\mathrm{a}}$ & $1^{\mathrm{a}}$ & $2^{\mathrm{c}}$ & $1^{\mathrm{a}}$ & $1^{\mathrm{a}}$ \\
ShiYingZi-TH & $1^{\mathrm{a}}$ & $2^{\mathrm{b}}$ & $2^{\mathrm{c}}$ & $2^{\mathrm{c}}$ & $0^{\mathrm{a}}$ \\
Sulfachloropyrazine sodium & $0^{\mathrm{a}}$ & $1^{\mathrm{a}}$ & $2^{\mathrm{c}}$ & $1^{\mathrm{a}}$ & $0^{\mathrm{a}}$ \\
\hline
\end{tabular}

$\mathrm{a}, \mathrm{b}, \mathrm{c}$ Different letters indicate that a significant difference existed $(p<0.05)$.

Table 3. The number of oocysts per gram of feces $\left(\times 10^{6}\right)$.

\begin{tabular}{cccccc}
\hline Groups & $\mathbf{4} \mathbf{d p i}$ & $\mathbf{5} \mathbf{d p i}$ & $\mathbf{6} \mathbf{d p i}$ & $\mathbf{7} \mathbf{d p i}$ & $\mathbf{8} \mathbf{d p i}$ \\
\hline Uninfected-untreated control & 0 & 0 & 0 & 0 & 0 \\
Infected-untreated control & 0.27 & 2.78 & 1.93 & 1.54 & 1.15 \\
ShiYingZi-PL & 0.09 & 2 & 1.71 & 0.85 & 0.55 \\
ShiYingZi-PM & 0.14 & 2.13 & 1.24 & 1.03 & 0.60 \\
ShiYingZi-PH & 0 & 3.12 & 1.75 & 1.06 & 0.83 \\
Monensin & 0 & 1.56 & 1.69 & 0.75 & 0.42 \\
ShiYingZi-TL & 0.21 & 2.17 & 1.78 & 1.13 & 0.90 \\
ShiYingZi-TM & 0.33 & 2.33 & 1.51 & 1.23 & 0.95 \\
ShiYingZi-TH & 0.25 & 2.49 & 1.88 & 1.07 & 0.46 \\
Sulfachloropyrazine sodium & 0.19 & 2.12 & 1.25 & 0.99 & 0.78 \\
\hline
\end{tabular}

Coccidiosis induced decreased weight gain, and the relative weight gain rate was 53\% compared with the uninfected-untreated group (Table 4). The prophylactic administration of "Shi Ying Zi" powder could recover the relative weight gain rate up to $86 \%$ compared with the uninfected-untreated group, which is better than monensin. The relative weight gain rate of the "Shi Ying $\mathrm{Zi}^{\prime}$ powder therapeutic group could reach to $77 \%$ in comparison with the infected-untreated group. The gross lesions score and cecum oocyst index were decreased after the prophylactic and therapeutic administration of "Shi Ying Zi" powder and the positive drugs. The prophylactic administration of "Shi Ying Zi" powder at the dose of $10 \mathrm{~g} / \mathrm{kg}$ showed the highest anticoccidial activity, with an ACI value of 165, which is higher than that obtained for monensin (159). 
Table 4. Anti-coccidiosis index.

\begin{tabular}{|c|c|c|c|c|c|c|c|c|c|c|}
\hline \multirow[b]{2}{*}{ Indicators } & \multirow{2}{*}{$\begin{array}{c}\text { Uninfected- } \\
\text { Untreated Control }\end{array}$} & \multirow{2}{*}{$\begin{array}{c}\text { Infected- } \\
\text { Untreated Control }\end{array}$} & \multicolumn{4}{|c|}{ Protective Effect } & \multicolumn{4}{|c|}{ Therapeutic Effect } \\
\hline & & & ShiYingZi-PL & ShiYingZi-PM & ShiYingZi-PH & Monensin & ShiYingZi-TL & ShiYingZi-TM & ShiYingZi-TH & $\begin{array}{l}\text { Sulfachloropyrazine } \\
\text { Sodium }\end{array}$ \\
\hline $\begin{array}{l}\text { Average initial } \\
\text { weight/g }\end{array}$ & $165.27 \pm 20.5$ & $157.07 \pm 25.1$ & $164.07 \pm 20.72$ & $155.13 \pm 14.17$ & $160.43 \pm 14.98$ & $146.33 \pm 12.56$ & $160.13 \pm 18.12$ & $152.4 \pm 18.72$ & $149.33 \pm 19.29$ & $159.2 \pm 19.93$ \\
\hline $\begin{array}{l}\text { Average final } \\
\text { weight/g }\end{array}$ & $225 \pm 26.06^{b}$ & $189.14 \pm 29.44^{\mathrm{a}}$ & $210.27 \pm 22.29 \mathrm{ab}$ & $204.82 \pm 18.07^{\mathrm{ab}}$ & $209.41 \pm 16.57^{\mathrm{ab}}$ & $191.6 \pm 14.9^{\mathrm{a}}$ & $204 \pm 21.01^{\mathrm{a}}$ & $188.73 \pm 23.08^{\mathrm{a}}$ & $189.91 \pm 23.4^{\mathrm{a}}$ & $207.44 \pm 17.9^{a b}$ \\
\hline $\begin{array}{l}\text { Relative weight gain } \\
\text { rate }(\%)\end{array}$ & 100 & 53 & 78 & 86 & 83 & 78 & 74 & 71 & 77 & 80 \\
\hline Survival rate (\%) & 100 & 75 & 95 & 100 & 95 & 100 & 90 & 95 & 100 & 100 \\
\hline Gross lesions score & $0 \pm 0^{\mathrm{a}}$ & $35 \pm 5.27^{c}$ & $14 \pm 11.74^{\mathrm{b}}$ & $11 \pm 9.94^{b}$ & $14 \pm 11.74^{\mathrm{b}}$ & $9 \pm 8.76^{b}$ & $19 \pm 13.7^{b}$ & $15 \pm 10.8^{b}$ & $13 \pm 4.83^{b}$ & $11 \pm 7.38^{b}$ \\
\hline Cecum oocyst index & 0 & 40 & 20 & 10 & 10 & 10 & 20 & 20 & 20 & 10 \\
\hline $\mathrm{ACI}$ & - & - & 139 & 165 & 154 & 159 & 125 & 131 & 144 & 159 \\
\hline $\begin{array}{l}\text { Therapeutic } \\
\text { evaluation }\end{array}$ & - & - & low & medium & low & low & low & low & low & low \\
\hline
\end{tabular}

$\mathrm{a}, \mathrm{b}, \mathrm{c}$ Significant differences exist when there are different letters in each column $(p<0.05) . n=20$. The initial weight was the weight on the day of infection and the final weight was the weight at $8 \mathrm{dpi}$. 


\subsection{Biochemical Indexes}

The contents of total protein (Table 5), albumin (Table 6), and triglyceride (Table 7) were decreased after infection on 4 and 8 dpi $(p<0.05)$, but they were increased after pretreatment or treatment with "Shi Ying $\mathrm{Zi}$ " powder and positive drugs $(p<0.05)$. The serum globulin concentrations (Table 8 ) in the infected chicks with or without treatment were increased on 4 and $8 \mathrm{dpi}(p<0.05)$, and no significant difference was observed among all of the infected chicks. The contents of alanine aminotransferase (Table 9) and creatinine (Table 10) in the infected chicks were increased on 4 and 8 dpi $(p<0.05)$, and after the prophylactic and therapeutic administration of "Shi Ying Zi" powder, they were decreased $(p<0.05)$. Coccidiosis led to an increased $(p<0.05)$ content of aspartate aminotransferase on 4 and $8 \mathrm{dpi}$ (Table 11), and after the prophylactic and therapeutic administration of "Shi Ying Zi" powder, it was decreased on $8 \mathrm{dpi}(p<0.05)$.

\subsection{Histopathological Examination}

In the cecum, oocysts invaded the cecum mucosa and intestinal gland (Figure 1B), and serious karyopyknosis and necrocytosis were detected in cecum mucosa cells. In the ShiYingZi-PM group (Figure 1C), ShiYingZi-TH group (Figure 1E), and positive control groups (Figure 1D, monensin; Figure $1 \mathrm{~F}$, sulfachloropyrazine sodium), few oocysts were observed in the cecum mucosa cells, and the cecum mucosa cells were granular and exhibited vacuolar degeneration; in the uninfected-untreated group (Figure 1A), the cecum displayed a normal structure.

Table 5. Total protein content $(\mathrm{g} / \mathrm{L})$.

\begin{tabular}{cccc}
\hline Groups & $\mathbf{1 ~ d p i}$ & $\mathbf{4} \mathbf{d p i}$ & $\mathbf{8} \mathbf{d p i}$ \\
\hline Uninfected-untreated control & $24.56 \pm 1.43^{\mathrm{a}}$ & $25.26 \pm 1.16^{\mathrm{c}}$ & $25.48 \pm 1.23^{\mathrm{b}}$ \\
Infected-untreated control & $25.48 \pm 2.35^{\mathrm{a}}$ & $21.58 \pm 1^{\mathrm{a}}$ & $20.94 \pm 0.98^{\mathrm{a}}$ \\
ShiYingZi-PL & $24.8 \pm 1.02^{\mathrm{a}}$ & $23.52 \pm 0.82^{\mathrm{b}}$ & $27.4 \pm 2.33^{\mathrm{bc}}$ \\
ShiYingZi-PM & $23.66 \pm 2.19^{\mathrm{a}}$ & $24.28 \pm 1.01^{\mathrm{bc}}$ & $28.62 \pm 1.42^{\mathrm{c}}$ \\
ShiYingZi-PH & $24.3 \pm 0.92^{\mathrm{a}}$ & $25.22 \pm 1.35^{\mathrm{c}}$ & $28.08 \pm 1.98^{\mathrm{c}}$ \\
Monensin & $23.6 \pm 1.98^{\mathrm{a}}$ & $23.64 \pm 1.43^{\mathrm{b}}$ & $28.14 \pm 0.8^{\mathrm{c}}$ \\
ShiYingZi-TL & $23.67 \pm 2.23^{\mathrm{a}}$ & $20.67 \pm 1.72^{\mathrm{a}}$ & $24.13 \pm 1.43^{\mathrm{b}}$ \\
ShiYingZi-TM & $23.1 \pm 0.95^{\mathrm{a}}$ & $21.73 \pm 1.40^{\mathrm{a}}$ & $23.63 \pm 1.68^{\mathrm{b}}$ \\
ShiYingZi-TH & $24.40 \pm 0.92^{\mathrm{a}}$ & $21.47 \pm 3.00^{\mathrm{a}}$ & $25.23 \pm 1.22^{\mathrm{b}}$ \\
Sulfachloropyrazine sodium & $24.27 \pm 3.40^{\mathrm{a}}$ & $22.67 \pm 0.57^{\mathrm{a}}$ & $25.80 \pm 2.19^{\mathrm{b}}$ \\
\hline a,b,c Significant differences exist when there are different letters in each column $(p<0.05) . n=5$.
\end{tabular}

$\mathrm{a}, \mathrm{b}, \mathrm{c}$ Significant differences exist when there are different letters in each column $(p<0.05) . n=5$.

Table 6. The albumin content $(\mathrm{g} / \mathrm{L})$.

\begin{tabular}{cccc}
\hline Groups & $\mathbf{1 ~ d \mathbf { p i }}$ & $\mathbf{4} \mathbf{d p i}$ & $\mathbf{8} \mathbf{d p i}$ \\
\hline Uninfected-untreated control & $11.78 \pm 0.79^{\mathrm{a}}$ & $12.34 \pm 0.84^{\mathrm{c}}$ & $13.74 \pm 1.03^{\mathrm{c}}$ \\
Infected-untreated control & $11.78 \pm 1.11^{\mathrm{a}}$ & $4.64 \pm 0.61^{\mathrm{a}}$ & $4.82 \pm 1.36^{\mathrm{a}}$ \\
ShiYingZi-PL & $10.9 \pm 1.51^{\mathrm{a}}$ & $6.1 \pm 0.68^{\mathrm{b}}$ & $10.42 \pm 0.87^{\mathrm{b}}$ \\
ShiYingZi-PM & $10.48 \pm 2.02^{\mathrm{a}}$ & $7.44 \pm 0.8^{\mathrm{b}}$ & $11.04 \pm 0.87^{\mathrm{b}}$ \\
ShiYingZi-PH & $11.3 \pm 0.89^{\mathrm{a}}$ & $7.24 \pm 1.39^{\mathrm{b}}$ & $11.26 \pm 0.63^{\mathrm{b}}$ \\
Monensin & $10.8 \pm 0.99^{\mathrm{a}}$ & $6.6 \pm 1.44^{\mathrm{b}}$ & $11.46 \pm 1.33^{\mathrm{b}}$ \\
ShiYingZi-TL & $10.73 \pm 1.58^{\mathrm{a}}$ & $4.10 \pm 0.92^{\mathrm{a}}$ & $8.40 \pm 0.92^{\mathrm{b}}$ \\
ShiYingZi-TM & $10.90 \pm 0.56^{\mathrm{a}}$ & $4.57 \pm 0.61^{\mathrm{a}}$ & $7.80 \pm 0.61^{\mathrm{b}}$ \\
ShiYingZi-TH & $11.67 \pm 1.80^{\mathrm{a}}$ & $6.00 \pm 1.25^{\mathrm{a}}$ & $7.20 \pm 1.25^{\mathrm{b}}$ \\
Sulfachloropyrazine sodium & $11.53 \pm 2.87^{\mathrm{a}}$ & $6.20 \pm 1.00^{\mathrm{a}}$ & $9.43 \pm 1.00^{\mathrm{b}}$ \\
\hline a,b,c Significat diffencs &
\end{tabular}

$\mathrm{a}, \mathrm{b}, \mathrm{c}$ Significant differences exist when there are different letters in each column $(p<0.05) . n=5$. 
Table 7. Triglyceride content ( $\mathrm{mmol} / \mathrm{L})$.

\begin{tabular}{cccc}
\hline Groups & $\mathbf{1 ~ d p i}$ & $\mathbf{4} \mathbf{d p i}$ & $\mathbf{8} \mathbf{d p i}$ \\
\hline Uninfected-untreated control & $0.57 \pm 0.06^{\mathrm{a}}$ & $0.59 \pm 0.04^{\mathrm{c}}$ & $0.57 \pm 0.07^{\mathrm{c}}$ \\
Infected-untreated control & $0.57 \pm 0.08^{\mathrm{a}}$ & $0.38 \pm 0.04^{\mathrm{a}}$ & $0.34 \pm 0.05^{\mathrm{a}}$ \\
ShiYingZi-PL & $0.56 \pm 0.03^{\mathrm{a}}$ & $0.44 \pm 0.03^{\mathrm{b}}$ & $0.47 \pm 0.03^{\mathrm{b}}$ \\
ShiYingZi-PM & $0.54 \pm 0.05^{\mathrm{a}}$ & $0.49 \pm 0.04^{\mathrm{b}}$ & $0.48 \pm 0.03^{\mathrm{b}}$ \\
ShiYingZi-PH & $0.56 \pm 0.07^{\mathrm{a}}$ & $0.47 \pm 0.04^{\mathrm{b}}$ & $0.47 \pm 0.04^{\mathrm{b}}$ \\
Monensin & $0.57 \pm 0.06^{\mathrm{a}}$ & $0.48 \pm 0.05^{\mathrm{b}}$ & $0.45 \pm 0.04^{\mathrm{b}}$ \\
ShiYingZi-TL & $0.55 \pm 0.05^{\mathrm{a}}$ & $0.39 \pm 0.04^{\mathrm{a}}$ & $0.40 \pm 0.06^{\mathrm{ab}}$ \\
ShiYingZi-TM & $0.54 \pm 0.06^{\mathrm{a}}$ & $0.36 \pm 0.03^{\mathrm{a}}$ & $0.41 \pm 0.03^{\mathrm{ab}}$ \\
ShiYingZi-TH & $0.53 \pm 0.09^{\mathrm{a}}$ & $0.38 \pm 0.07^{\mathrm{a}}$ & $0.46 \pm 0.04^{\mathrm{b}}$ \\
Sulfachloropyrazine sodium & $0.56 \pm 0.05^{\mathrm{a}}$ & $0.37 \pm 0.04^{\mathrm{a}}$ & $0.45 \pm 0.04^{\mathrm{b}}$ \\
\hline a,b,c Significant differences exist when there are different letters in each column $(p<0.05) . n=5$.
\end{tabular}

Table 8. The globulin content $(\mathrm{g} / \mathrm{L})$.

\begin{tabular}{cccc}
\hline Groups & $\mathbf{1} \mathbf{d p i}$ & $\mathbf{4} \mathbf{d p i}$ & $\mathbf{8} \mathbf{d p i}$ \\
\hline Uninfected-untreated control & $12.78 \pm 0.85^{\mathrm{a}}$ & $12.92 \pm 0.69^{\mathrm{a}}$ & $11.76 \pm 0.87^{\mathrm{a}}$ \\
Infected-untreated control & $12.78 \pm 0.86^{\mathrm{a}}$ & $16.94 \pm 1.38^{\mathrm{b}}$ & $16.10 \pm 0.58^{\mathrm{b}}$ \\
ShiYingZi-PL & $13.9 \pm 2.09^{\mathrm{a}}$ & $17.42 \pm 0.53^{\mathrm{b}}$ & $16.98 \pm 1.65^{\mathrm{b}}$ \\
ShiYingZi-PM & $13.18 \pm 1.45^{\mathrm{a}}$ & $16.84 \pm 0.3^{\mathrm{b}}$ & $17.58 \pm 0.89^{\mathrm{b}}$ \\
ShiYingZi-PH & $13.00 \pm 0.74^{\mathrm{a}}$ & $17.96 \pm 0.8^{\mathrm{b}}$ & $16.82 \pm 1.5^{\mathrm{b}}$ \\
Monensin & $12.8 \pm 1.31^{\mathrm{a}}$ & $17.04 \pm 0.78^{\mathrm{b}}$ & $16.68 \pm 0.9^{\mathrm{b}}$ \\
ShiYingZi-TL & $12.93 \pm 1.77^{\mathrm{a}}$ & $16.57 \pm 2.57^{\mathrm{b}}$ & $15.73 \pm 1.65^{\mathrm{b}}$ \\
ShiYingZi-TM & $12.20 \pm 0.46^{\mathrm{a}}$ & $17.17 \pm 0.83^{\mathrm{b}}$ & $15.83 \pm 2.94^{\mathrm{b}}$ \\
ShiYingZi-TH & $12.70 \pm 1.97^{\mathrm{a}}$ & $15.47 \pm 1.76^{\mathrm{b}}$ & $18.03 \pm 0.80^{\mathrm{b}}$ \\
Sulfachloropyrazine sodium & $12.73 \pm 1.83^{\mathrm{a}}$ & $16.47 \pm 1.56^{\mathrm{b}}$ & $16.37 \pm 0.86^{\mathrm{b}}$ \\
\hline a,b,c Significant differences exist when there are different letters in each column $(p<0.05) . n=5$.
\end{tabular}

Table 9. The alanine aminotransferase content (U/L).

\begin{tabular}{cccc}
\hline Groups & 1 dpi & $\mathbf{4} \mathbf{d p i}$ & $\mathbf{8} \mathbf{d p i}$ \\
\hline Uninfected-untreated control & $4.18 \pm 0.31^{\mathrm{a}}$ & $4.08 \pm 0.22^{\mathrm{a}}$ & $4.14 \pm 0.23^{\mathrm{a}}$ \\
Infected-untreated control & $4.08 \pm 0.53^{\mathrm{a}}$ & $5.6 \pm 0.5^{\mathrm{b}}$ & $6.06 \pm 0.21^{\mathrm{c}}$ \\
ShiYingZi-PL & $4.1 \pm 0.37^{\mathrm{a}}$ & $4.66 \pm 0.15^{\mathrm{a}}$ & $4.78 \pm 0.23^{\mathrm{b}}$ \\
ShiYingZi-PM & $4.34 \pm 0.49^{\mathrm{a}}$ & $4.64 \pm 0.32^{\mathrm{a}}$ & $4.34 \pm 0.15^{\mathrm{a}}$ \\
ShiYingZi-PH & $4.14 \pm 0.45^{\mathrm{a}}$ & $4.66 \pm 0.21^{\mathrm{a}}$ & $4.34 \pm 0.15^{\mathrm{a}}$ \\
Monensin & $4.16 \pm 0.54^{\mathrm{a}}$ & $4.5 \pm 0.25^{\mathrm{a}}$ & $4.24 \pm 0.26^{\mathrm{a}}$ \\
ShiYingZi-TL & $4.30 \pm 0.78^{\mathrm{a}}$ & $5.53 \pm 0.32^{\mathrm{b}}$ & $5.13 \pm 0.15^{\mathrm{b}}$ \\
ShiYingZi-TM & $4.16 \pm 0.35^{\mathrm{a}}$ & $5.16 \pm 0.67^{\mathrm{b}}$ & $4.93 \pm 0.35^{\mathrm{b}}$ \\
ShiYingZi-TH & $4.57 \pm 0.61^{\mathrm{a}}$ & $5.33 \pm 0.41^{\mathrm{b}}$ & $4.80 \pm 0.60^{\mathrm{a}}$ \\
Sulfachloropyrazine sodium & $4.60 \pm 0.35^{\mathrm{a}}$ & $5.03 \pm 067^{\mathrm{b}}$ & $4.83 \pm 0.60^{\mathrm{a}}$ \\
\hline a,b,c Significant differences
\end{tabular}

$\mathrm{a}, \mathrm{b}, \mathrm{c}$ Significant differences exist when there are different letters in each column $(p<0.05) . n=5$. 
Table 10. The creatinine content $(\mu \mathrm{mol} / \mathrm{L})$.

\begin{tabular}{cccc}
\hline Groups & $\mathbf{1 ~ d \mathbf { ~ p i }}$ & $\mathbf{4} \mathbf{d p i}$ & $\mathbf{8} \mathbf{d p i}$ \\
\hline Uninfected-untreated control & $18.02 \pm 2.27^{\mathrm{a}}$ & $17.48 \pm 1.28^{\mathrm{a}}$ & $17.08 \pm 2.16^{\mathrm{a}}$ \\
Infected-untreated control & $17.98 \pm 2.16^{\mathrm{a}}$ & $26.62 \pm 3.46^{\mathrm{c}}$ & $28 \pm 3.17^{\mathrm{c}}$ \\
ShiYingZi-PL & $18.34 \pm 1.4^{\mathrm{a}}$ & $23.1 \pm 3.49^{\mathrm{b}}$ & $22.36 \pm 1.67^{\mathrm{b}}$ \\
ShiYingZi-PM & $18.34 \pm 1.78^{\mathrm{a}}$ & $22.18 \pm 2.04^{\mathrm{b}}$ & $20.98 \pm 1.2^{\mathrm{b}}$ \\
ShiYingZi-PH & $18.18 \pm 2.53^{\mathrm{a}}$ & $21.4 \pm 1.78^{\mathrm{b}}$ & $21.36 \pm 1.53^{\mathrm{b}}$ \\
Monensin & $18.52 \pm 1.43^{\mathrm{a}}$ & $23.42 \pm 1.54^{\mathrm{b}}$ & $21.04 \pm 1.23^{\mathrm{b}}$ \\
ShiYingZi-TL & $17.50 \pm 1.90^{\mathrm{a}}$ & $25.03 \pm 1.77^{\mathrm{b}}$ & $22.73 \pm 1.71^{\mathrm{b}}$ \\
ShiYingZi-TM & $19.13 \pm 1.72^{\mathrm{a}}$ & $24.86 \pm 3.22^{\mathrm{b}}$ & $23.66 \pm 1.59^{\mathrm{b}}$ \\
ShiYingZi-TH & $18.56 \pm 2.00^{\mathrm{a}}$ & $24.46 \pm 1.60^{\mathrm{b}}$ & $23.70 \pm 1.83^{\mathrm{b}}$ \\
Sulfachloropyrazine sodium & $19.76 \pm 1.04^{\mathrm{a}}$ & $25.40 \pm 2.52^{\mathrm{b}}$ & $21.56 \pm 2.33^{\mathrm{b}}$ \\
\hline a,b,c Significant differences exist when there are different letters in each column $(p<0.05) . n=5$.
\end{tabular}

Table 11. The aspartate aminotransferase content (U/L).

\begin{tabular}{cccc}
\hline Groups & $\mathbf{1 ~ d p i}$ & $\mathbf{4} \mathbf{d p i}$ & $\mathbf{8} \mathbf{d p i}$ \\
\hline Uninfected-untreated control & $220.46 \pm 11.77^{\mathrm{a}}$ & $223.22 \pm 12.06^{\mathrm{a}}$ & $230.62 \pm 23.95^{\mathrm{a}}$ \\
Infected-untreated control & $222.56 \pm 14.18^{\mathrm{a}}$ & $263.46 \pm 9.28^{\mathrm{b}}$ & $275.9 \pm 10.79^{\mathrm{c}}$ \\
ShiYingZi-PL & $216.3 \pm 13.94^{\mathrm{a}}$ & $256.66 \pm 11.08^{\mathrm{b}}$ & $259.28 \pm 7.49^{\mathrm{b}}$ \\
ShiYingZi-PM & $214.38 \pm 17.06^{\mathrm{a}}$ & $254.54 \pm 7.25^{\mathrm{b}}$ & $250.12 \pm 5.36^{\mathrm{b}}$ \\
ShiYingZi-PH & $214.1 \pm 14.39^{\mathrm{a}}$ & $251.3 \pm 7.11^{\mathrm{b}}$ & $251.32 \pm 12.03^{\mathrm{b}}$ \\
Monensin & $224.34 \pm 8.5^{\mathrm{a}}$ & $263.3 \pm 11.9^{\mathrm{b}}$ & $253.08 \pm 6.31^{\mathrm{b}}$ \\
ShiYingZi-TL & $224.20 \pm 9.78^{\mathrm{a}}$ & $258.33 \pm 10.69^{\mathrm{b}}$ & $264.03 \pm 9.18^{\mathrm{b}}$ \\
ShiYingZi-TM & $232.33 \pm 8.88^{\mathrm{a}}$ & $263.73 \pm 16.22^{\mathrm{b}}$ & $267.37 \pm 20.15^{\mathrm{b}}$ \\
ShiYingZi-TH & $220.50 \pm 11.05^{\mathrm{a}}$ & $264.50 \pm 9.97^{\mathrm{b}}$ & $264.43 \pm 21.63^{\mathrm{b}}$ \\
Sulfachloropyrazine sodium & $230.50 \pm 9.10^{\mathrm{a}}$ & $263.43 \pm 19.90^{\mathrm{b}}$ & $254.07 \pm 0.36^{\mathrm{b}}$ \\
\hline a,b,c Significant differences exist when there are different letters in each column $(p<0.05) . n=5$.
\end{tabular}

In the liver, E. tenella infection induced serious hepatocyte necrosis and inflammatory cell infiltration (Figure 1H); granular and vacuolar degeneration appeared in the ShiYingZi-PM group (Figure 1I), ShiYingZi-TH group (Figure 1K), and positive control groups (Figure 1J, monensin; Figure 1L, sulfachloropyrazine sodium); without infection, the liver showed a normal structure (Figure 1G).

In the kidney, serious granular and vacuolar degeneration and cell necrosis were observed in the infected-untreated group (Figure 1N); mild granular and vacuolar degeneration were observed in the ShiYingZi-PM group (Figure 1O), ShiYingZi-TH group (Figure 1Q), and positive control groups (Figure 1P, monensin; Figure 1R, sulfachloropyrazine sodium); more severe inflammatory cell infiltration was observed in the sulfachloropyrazine sodium group (Figure 1R) than that in the ShiYingZi-TH group (Figure 1Q); and without infection, the kidney showed a normal structure (Figure 1I). 


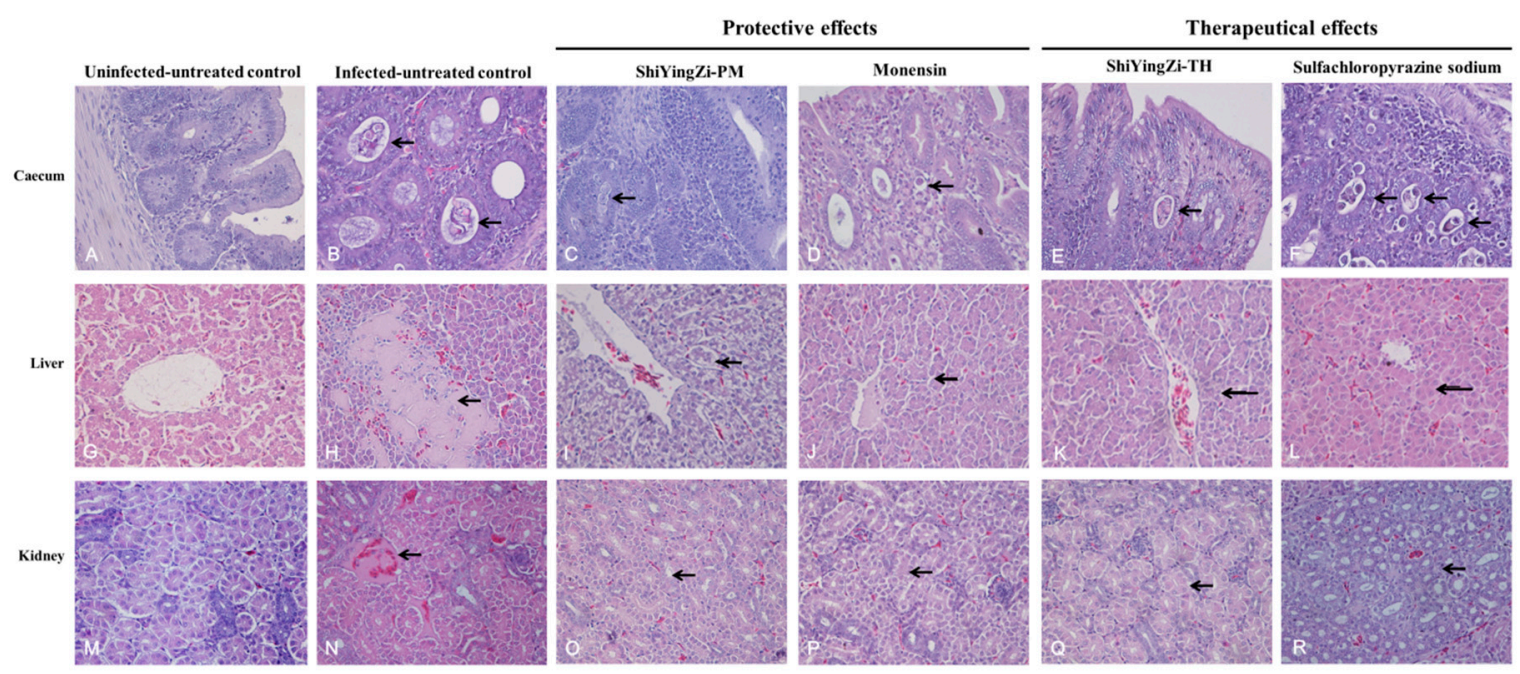

Figure 1. Histopathological examination (400×). In the cecum (A-F), oocysts invaded the cecum mucosa and intestinal gland ((B), denoted by an arrowhead) and serious karyopyknosis and necrocytosis were detected in cecum mucosa cells; in the ShiYingZi-PM group (C), ShiYingZi-TH group (E), and positive control groups ((D), monensin; (F), sulfachloropyrazine sodium), few oocysts were observed in cecum mucosa cells (denoted by an arrowhead), and the cecum mucosa cells were granular and exhibited vacuolar degeneration; (A) the uninfected-untreated group. In the liver (G-L), Eimeria tenella infection induced serious hepatocyte necrosis and inflammatory cell infiltration $((\mathbf{H})$, denoted by arrowhead); granular and vacuolar degeneration (denoted by arrowhead) appeared in the ShiYingZi-PM group (I), positive control group ((J), monensin; (L), sulfachloropyrazine sodium), and ShiYingZi-TH group (K); (G) the normal structure of the liver. In the kidney (M-R), serious granular and vacuolar degeneration and cell necrosis were observed in the infected-untreated group $((\mathbf{N})$, denoted by arrowhead); little granular and vacuolar degeneration (denoted by an arrowhead) was observed in the ShiYingZi-PM group $(\mathbf{O})$, ShiYingZi-TH group $(\mathbf{Q})$, and positive control group $((\mathbf{P})$, monensin; (R), sulfachloropyrazine sodium); in terms of the therapeutic effects, more inflammatory cell infiltration was observed in the positive control group (R) than in the ShiYingZi-TH group (Q); (M) the uninfected-untreated group.

\section{Discussion}

Coccidiosis is one of the most economically important diseases, but commonly used anti-coccidiosis drugs often cause drug residues in meat and eggs [26]. This study provides a new herbal drug

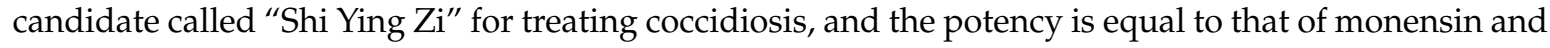
sulfamlopyrazine. Unlike other herbal medicine, "Shi Ying $\mathrm{Zi}^{\prime}$ does not need any extraction process and it is the powder of C. monnieri, T. mongolicum, and sodium chloride. Therefore, it is more financially acceptable, which is the one of the most important requirements for drugs used in the poultry industry. This study revealed that "Shi Ying Zi" powder administrated both prior to and after infection showed potent anticoccidial effects, suggesting that it could be used as a prophylactic and therapeutic drug. For prophylaxis, the recommended dosage of "Shi Ying Zi " powder is $10 \mathrm{~g} / \mathrm{kg}$; for treatment, it is $15 \mathrm{~g} / \mathrm{kg}$.

Coccidiosis usually reduces the body weight gain in broiler chicks as a result of a reduced feed intake, digestibility, and absorption of macronutrients [27]. It is accepted that weight gain is the more sensitive variable to coccidiosis and anticoccidial treatments [28]. When infective sporozoites enter the cecum mucosa by penetrating villus epithelial cells, this leads to extensive destruction of the cecum epithelium, bloody stools, and a large amount of oocyst excretion [29,30]. In this study, infected chicks were dull and depressed, exhibiting disheveled feathers and a lower feed intake, which may have been due to altered gut homeostasis that led to poor feed intake and metabolism and thus decreased weight gains [31,32]. "Shi Ying Zi" powder can alleviate the histopathological changes of the cecum, and the number of oocysts and mucosa cell necrocytosis in the cecum were decreased. Therefore, 
the relative weight gain rates of "Shi Ying Z" groups were also improved. The anti-coccidial index is a common index employed to evaluate the anticoccidial activity of drugs. The ACI was 165 in the "Shi Ying Z" protective group $(10 \mathrm{~g} / \mathrm{kg})$, which is higher than the value for the positive control monensin. These results suggested that "Shi Ying $\mathrm{Zi}^{\mathrm{i}}$ powder is a moderate-potency anticoccidial drug.

The blood biochemical analysis reflected alterations of functional organs and some enzyme activities are often used as indicators of the site and the extent of pathological injury $[33,34]$. The infection of coccidiosis can affect the body's liver function, which leads to a decrease of the triglyceride content in the serum [7]. The nutrient malabsorption, hepatocellular damage, hemorrhagic enteritis, kidney dysfunction, and inappetence might lead to a decrease of the serum albumin and total protein content $[31,35]$ and an increase of the alanine aminotransferase and aspartate amino transferase contents in the serum [36]. Similarly, there was a significant decrease in the contents of albumin, total protein, and triglyceride and a significant increase in the contents of alanine aminotransferase and aspartate amino transferase after infection. After prophylaxis or treatment with "Shi Ying Zi" powder, these changed biochemical parameters were recovered towards normal levels. In the histopathological study, serious liver damage after E. tenella infection could be observed, while "Shi Ying Zi" powder could alleviate these symptoms. These results suggested that coccidiosis could affect the body's liver function, and "Shi Ying Zi" powder could protect and alleviate the liver damage.

Creatinine is a metabolite of muscle creatine and phosphate, which is not affected by the food protein content and protein metabolism. The content of creatinine in the body is relatively constant and only reflected by the renal clearance and renal function $[37,38]$. In the case of renal insufficiency, creatinine accumulates in the body and becomes a toxin that is harmful to the body, so the creatinine content can respond to the damage to renal parenchyma [39]. There was a significant increase in creatinine after infection, which was consistent with a previous report [40]. The content of creatinine in the ShiYingZi-treated group was significantly lower. These results showed that "Shi Ying Zi" powder could protect the kidney damage caused by coccidiosis.

Traditional Chinese medicine (TCM) formulas usually exhibit numerous pharmacological effects due to multiple components and targets [41]. It has been revealed that a T. mongolicum extract could inhibit coccidian oocyst sporulation [42] and reduce liver injury induced by alcohol and environmental pollutants $[43,44]$. Chlorogenic acid and caffeic acid, which are the main components of T. mongolicum, also contributed to the anticoccidial efficacy of a herbal formula [19]. In China, C. monnieri is used to treat coccidiosis in many TCM prescriptions [45] and can improve the kidney function in kidney yang deficient mice [14]. Osthole, which is the main active constituent, is also beneficial for fatty liver [46]. The herbal formula called "Shi Ying $\mathrm{Zi}^{\mathrm{i}}$ presented in this study showed multidirectional activity, which may be attributed to the multiple components and biological activities of $C$. monnieri and T. mongolicum, such as chlorogenic acid, caffeic acid, and osthole. Further study should be conducted

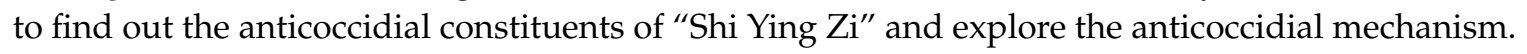

\section{Conclusions}

The traditional Chinese medicine formula "Shi Ying Zi" powder can prevent and treat E. tenella

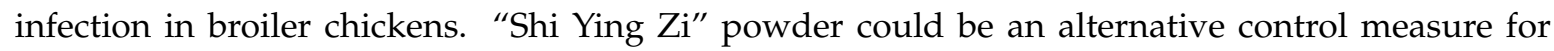
E. tenella infection.

Supplementary Materials: The following are available online at http:/www.mdpi.com/2076-2615/10/9/1484/s1, Table S1: Nutritional components of the diet.

Author Contributions: Conceptualization, R.J.; formal analysis, L.L.; investigation, X.S., Y.L., and S.C.; methodology, Y.H.; project administration, Y.Z.; resources, X.Z.; supervision, Z.Y.; writing-original draft, X.S.; writing - review and editing, Z.Y. All authors have read and agreed to the published version of the manuscript.

Funding: This research was financially supported by the Program Sichuan Veterinary Medicine and Drug Innovation Group of China Agricultural Research System (SCCXTD-2020-18), and the Science and Technology Project of Sichuan Province (Grant Nos. 2018NZ0043 and 2018NZ0064). The funding body does not have any roles in the design of the study; in the collection, analysis, and interpretation of data; and in writing of the manuscript. 
Conflicts of Interest: The authors declare no conflict of interest.

\section{References}

1. Fatoba, A.; Adeleke, M.A. Diagnosis and control of chicken coccidiosis: A recent update. J. Parasit. Dis. 2018, 4, 483-493. [CrossRef]

2. Morris, G.M.; Gasser, R.B. Biotechnological advances in the diagnosis of avian coccidiosis and the analysis of genetic variation in Eimeria. Biotechnol. Adv. 2006, 6, 590-603. [CrossRef] [PubMed]

3. Shirley, M.W.; Smith, A.L.; Blake, D.P. Challenges in the successful control of the avian coccidia. Vaccine 2007, 30, 5540-5547. [CrossRef] [PubMed]

4. Jarujareet, W.; Kobayashi, M.; Taira, K.; Ooi, H.K. The role of the American cockroach (Periplaneta americana) as transport host of Eimeria tenella to chickens. Parasitol. Res. 2019, 118, 2311-2315. [CrossRef] [PubMed]

5. Yim, D.; Kang, S.S.; Kim, D.W.; Kim, S.H.; Lillehoj, H.S.; Min, W. Protective effects of Aloe vera-based diets in Eimeria maxima-infected broiler chickens. Exp. Parasitol. 2011, 1, 322-325. [CrossRef]

6. Chen, T.; Huang, B.; Zhao, Q.; Dong, H.; Zhu, S.; Zhao, Z.; Lv, L.; Yan, M.; Han, H. Molecular characterization and functional analysis of Eimeria tenella malate dehydrogenase. Parasitol. Res. 2018, 117, $2053-2063$. [CrossRef]

7. Akhtar, M.; Hai, A.; Awais, M.M.; Iqbal, Z.; Muhammad, F.; ul Haq, A.; Anwar, M.I. Immunostimulatory and protective effects of Aloe vera against coccidiosis in industrial broiler chickens. Vet. Parasitol. 2012, 186, 170-177. [CrossRef]

8. El-Abasy, M.; Motobu, M.; Na, K.J.; Shimura, K.; Nakamura, K.; Koge, K.; Onodera, T.; Hirota, Y. Protective Effects of Sugar Cane Extracts (SCE) on Eimeria tenella Infection in Chickens. J. Vet. Med. Sci. 2003, 65, 865-871. [CrossRef]

9. Pastor-Fernández, I.; Pegg, E.; Macdonald, S.E.; Tomley, F.M.; Blake, D.P.; Marugán-Hernández, V. Laboratory Growth and Genetic Manipulation of Eimeria tenella. Curr. Protoc. Microbiol. 2019, 53, e81. [CrossRef]

10. Debry, R.W. Identifying conflicting signal in a multigene analysis reveals a highly resolved tree: The phylogeny of Rodentia (Mammalia). Syst. Biol. 2003, 52, 604-617. [CrossRef]

11. Youn, H.J.; Noh, J.W. Screening of the anticoccidial effects of herb extracts against Eimeria tenella. Vet. Parasitol. 2011, 96, 257-263. [CrossRef]

12. Nweze, N.E.; Obiwulu, I.S. Anticoccidial effects of Ageratum conyzoides. J. Ethnopharmacol. 2009, 122, 6-9. [CrossRef] [PubMed]

13. Quiroz-Castaneda, R.E.; Dantan-Gonzalez, E. Control of avian coccidiosis: Future and present natural alternatives. Biomed. Res. Int. 2015, 2015, 430-610. [CrossRef] [PubMed]

14. Li, Y.M.; Jia, M.; Li, H.Q.; Zhang, N.D.; Wen, X.; Rahman, K.; Zhang, Q.Y.; Qin, L.P. Cnidium monnieri: A review of traditional uses, phytochemical and ethnopharmacological properties. Am. J. Chin. Med. 2015, 43, 835-877. [CrossRef] [PubMed]

15. Jia, M.; Li, Y.; Zhai, X.; Yang, Y.; Li, C.; Zhang, Q.; Qin, L. Qualitative Analysis and Quality Evaluation of Cnidium monnieri Using UHPLC-ESI-Q-TOF/MS. Chin. Herb. Med. 2016, 8, 323-330. [CrossRef]

16. Ma, C.; Zhu, L.; Wang, J.; He, H.; Chang, X.; Gao, J.; Shumin, W.; Yan, T. Anti-inflammatory effects of water extract of Taraxacum mongolicum hand-Mazz on lipopolysaccharide-induced inflammation in acute lung injury by suppressing PI3K/Akt/mTOR signaling pathway. J. Ethnopharmacol. 2015, 168, 349-355. [CrossRef]

17. Hu, C. Taraxacum: Phytochemistry and health benefits. Chin. Herb. Med. 2018, 10, 353-361. [CrossRef]

18. Su, H.; Liu, X.; Yan, W.; Shi, T.; Zhao, X.; Blake, D.P.; Tomley, F.M.; Suo, X. piggyBac transposon-mediated transgenesis in the apicomplexan parasite Eimeria tenella. PLoS ONE 2012, 7, e40075. [CrossRef]

19. Kumar, S.; Garg, R.; Moftah, A.; Clark, E.L.; Macdonald, S.E.; Chaudhry, A.S.; Sparagano, O.; Banerjee, P.S.; Kundu, K.; Tomley, F.M.; et al. An optimised protocol for molecular identification of Eimeria from chickens. Vet. Parasitol. 2014, 199, 24-31. [CrossRef]

20. Hodgson, J.N. Coccidiosis: Oocyst counting technique for coccidiostat evaluation. Exp. Parasitol. 1970, 28, 99-102. [CrossRef]

21. Long, P.L.; Millard, B.J.; Joyner, L.P.; Norton, C.C. A guide to laboratory techniques used in the study and diagnosis of avian coccidiosis. Folia. Vet. Lat. 1976, 6, 201-217. [PubMed] 
22. Jiang, S.; Mohammed, A.A.; Jacobs, J.A.; Cramer, T.A.; Cheng, H.W. Effect of synbiotics on thyroid hormones, intestinal histomorphology, and heat shock protein 70 expression in broiler chickens reared under cyclic heat stress. Poult. Sci. 2019, 99, 142-150. [CrossRef] [PubMed]

23. Ványi, A.; Sályi, G.; Majoros, G.; Glávits, R.; Sándor, G.; Bagó, G. Interaction of T-2 fusariotoxin and monensin in broiler chickens infected with Coccidia. Acta Vet. Hung. 1989, 37, 327-333. [PubMed]

24. Johnson, J.; Reid, W.M. Anticoccidial drugs: Lesion scoring techniques in battery and floor-pen experiments with chickens. Exp. Parasitol. 1970, 28, 30-36. [CrossRef]

25. De Pablos, L.M.; dos Santos, M.F.; Montero, E.; Garcia-Granados, A.; Parra, A.; Osuna, A. Anticoccidial activity of maslinic acid against infection with Eimeria tenella in chickens. Parasitol. Res. 2010, 107, 601-604. [CrossRef]

26. Pop, L.M.E.; Varga, M.; Coroian, M.E.; Nedișan, V.; Mircean, M.O.; Dumitrache, L.; Farczádi, I.; Fülöp, M.D.; Fazakas, C.M.; Györke, A. Efficacy of a commercial herbal formula in chicken experimental coccidiosis. Parasit. Vectors. 2019, 12, 343. [CrossRef]

27. Adams, C.; Vahl, H.A.; Veldman, A. Interaction between nutrition and Eimeria acervulina infection in broiler chickens: Diet compositions that improve fat digestion during Eimeria acervulina infection. Br. J. Nutr. 1996, 75, 875-880. [CrossRef]

28. Gerhold, R.W.; Fuller, A.L.; McDougald, L.R. Coccidiosis in the chukar partridge (Alectoris chukar): A survey of coccidiosis outbreaks and a test of anticoccidial drugs against Eimeria kofoidi. Avian. Dis. 2016, 60, 752-757. [CrossRef]

29. Kawazoe, U.; Fabio, J.D. Resistance to diclazuril in field isolates of Eimeria species obtained from commercial broiler flocks in Brazil. Avian. Pathol. 1994, 23, 305-311. [CrossRef]

30. Dutta, G.P.; Mohan, A.; Tripathi, R. Study of the Gametocytocidal/Sporontocidal Action of Qinghaosu (Artemisinin) by Electron Microscopy. J. Parasitol. 1990, 76, 849-852. [CrossRef]

31. Kettunen, H.; Tiihonen, K.; Peuranen, S.; Saarinen, M.T.; Remus, J.C. Dietary betaine accumulates in the liver and intestinal tissue and stabilizes the intestinal epithelial structure in healthy and coccidia-infected broiler chicks. Comp. Biochem. Physiol. A Mol. Integr. Physiol. 2001, 130, 759-769. [CrossRef]

32. Hosseini-Mansoub, N.; Bahrami, Y. Influence of dietary fish oil supplementation on humoral immune response and some selected biochemical parameters of broiler chickens. J. Agrobiol. 2011, 28, 67-77. [CrossRef]

33. Flora, S.J.; Dubey, R.; Kannan, G.M.; Chauhan, R.S.; Pant, B.P.; Jaiswal, D.K. Meso 2,3-dimercaptosuccinic acid (DMSA) and monoisoamyl DMSA effect on gallium arsenide induced pathological liver injury in rats. Toxicol. Lett. 2002, 132, 9-17. [CrossRef]

34. Cerrato, P.; Lentini, A.; Baima, C.; Grasso, M.; Azzaro, C.; Bosco, G.; Destefanis, E.; Benna, P.; Bergui, M.; Bergamasco, B. Hypogeusia and hearing loss in a patient with an inferior collicular infarction. Neurology 2005, 65, 1840-1841. [CrossRef]

35. Mondal, D.K.; Chattopadhyay, S.; Batabyal, S.; Bera, A.K.; Bhattacharya, D. Plasma biochemical indices at various stages of infection with a field isolate of Eimeria tenella in broiler chicken. Vet. World. 2011, 4, 404-409. [CrossRef]

36. Jafari, R.A.; Razi-Jalali, M.; Kiani, R. Effect of fresh dietary garlic powder on some of the serum biochemical parameters in broiler chicks. Compara. Clin. Pathol. 2011, 20, 295-297. [CrossRef]

37. Hirani, N.D.; Hasnani, J.J.; Dhami, A.J.; Khanna, K. Haemato-biochemical profile of broilers affected with coccidiosis. J. Vet. Parasitol. 2007, 21, 25-28.

38. Dwyer, B.K.; Gorman, M.; Carroll, I.R.; Druzin, M. Urinalysis vs urine protein-creatinine ratio to predict significant proteinuria in pregnancy. J. Perinatol. 2008, 28, 461-467. [CrossRef]

39. Liu, K.D.; Thompson, B.T.; Ancukiewicz, M.; Steingrub, J.S.; Douglas, I.S.; Matthay, M.A.; Wright, P.; Peterson, M.W.; Rock, P.; Hyzy, R.C.; et al. Acute kidney injury in patients with acute lung injury: Impact of fluid accumulation on classification of acute kidney injury and associated outcomes. Crit. Care. Med. 2011, 39, 2665-2671. [CrossRef]

40. Dar, S.A.; Verma, P.; Ashfaque, M.; Mir, I.A. Effect of garlic extract on haematobiochemical changes in Eimeria tenella infected broiler chicken. Natl. Acad. Sci. Lett. 2014, 37, 311-316. [CrossRef]

41. Wu, G.; Zhang, W.; Li, H. Application of metabolomics for unveiling the therapeutic role of traditional Chinese medicine in metabolic diseases. J. Ethnopharmacol. 2019, 242, 112057. [CrossRef] [PubMed] 
42. Zhang, G. Effects of Chinese herbal medicine on sporulation of rabbit coccidia oocysts. Xinjiang Anim. Husbandry. 2012, 7, 16-18.

43. Ou, Y.; Yoo, S.; Yoon, H.G.; Park, J.; Lee, Y.H.; Kim, S.; Oh, K.T.; Lee, J.; Cho, H.Y.; Jun, W. In vitro and in vivo hepatoprotective effects of the aqueous extract from Taraxacum officinale (dandelion) root against alcohol-induced oxidative stress. Food Chem. Toxicol. 2010, 48, 1632-1637.

44. Hfaiedh, M.; Brahmi, D.; Zourgui, L. Hepatoprotective effect of Taraxacum officinale leaf extract on sodium dichromate-induced liver injury in rats. Environ. Toxicol. 2016, 31, 339-349. [CrossRef] [PubMed]

45. Xiao, J. Empirical formula for treatment of livestock and poultry diseases. Guizhou Anim. Sci. Vet. Med. 2001, 1, 27.

46. Zhang, J.; Xue, J.; Wang, H.; Zhang, Y.; Xie, M. Osthole improves alcohol-induced fatty liver in mice by reduction of hepatic oxidative stress. Phytother. Res. 2011, 25, 638-643. [CrossRef]

(C) 2020 by the authors. Licensee MDPI, Basel, Switzerland. This article is an open access article distributed under the terms and conditions of the Creative Commons Attribution (CC BY) license (http://creativecommons.org/licenses/by/4.0/). 